Article

\title{
The New Distribution: Spatio-Temporal Analysis of Large Distribution Warehouse Premises in England and Wales
}

\author{
Paul Greenhalgh ${ }^{1, *}$, Helen M. King ${ }^{2}$, Kevin Muldoon-Smith ${ }^{1}$ and Josephine Ellis ${ }^{1}$ \\ ${ }^{1}$ Department of Architecture and Built Environment, Northumbria University, UK; \\ E-Mails: paul.greenhalgh@northumbria.ac.uk (P.G.), k.muldoon-smith@northumbria.ac.uk (K.M.-S.), \\ josephine.ellis@northumbria.ac.uk (J.E.) \\ 2 Department of Geography and Environmental Science, Northumbria University, UK; \\ E-Mail: helen.m.king@northumbria.ac.uk \\ * Corresponding author
}

Submitted: 26 February 2021 | Accepted: 1 June 2021 | Published: 23 September 2021

\begin{abstract}
This research addresses the deficit of empirical investigation of changes in industrial and warehouse property markets in the UK. It uses business rates (rating list) data for England and Wales to reveal changes in the quantum and distribution of premises over the last decade. Spatio-temporal analysis using geographical information systems identifies where new industrial and warehouse premises have been developed and examines spatial changes in the distribution of premises between the two sectors. The research focuses on the development of new large distribution warehouses (LDWs) to investigate whether there is a new pattern of warehouse premises located in close proximity to junctions on the national highway network. Findings confirm the emergence of a dynamic distribution warehouse property market where "super sheds" have been developed in areas with high levels of multi-modal connectivity. The comprehensive spatio-temporal analysis of all industrial and warehouse premises in England and Wales reconfigures the previously recognised Midlands "Golden Triangle" of distribution warehouses to a "Golden Pointer" and reveals the emergence of a rival "Northern Dumbbell" of distribution warehouse premises in the North of England. Further analysis using isochrones confirms that $85 \%$ of the population of Great Britain is situated within four hours average heavy goods vehicle drive time of these two concentrations of super sheds and over $60 \%$ of all LDWs floorspace is within 30 minutes' drive of intermodal rail freight interchanges.
\end{abstract}

\section{Keywords}

distribution warehouses; drive time; England; GIS; industrial; logistics; motorways; multi-modal; spatio-temporal; Wales

\section{Issue}

This article is part of the issue "Future Commercial and Industrial Areas" edited by Angela Million (TU Berlin, Germany) and Felix Bentlin (TU Berlin, Germany).

(C) 2021 by the authors; licensee Cogitatio (Lisbon, Portugal). This article is licensed under a Creative Commons Attribution 4.0 International License (CC BY).

\section{Introduction and Context}

In recent decades there have been structural changes in the nature of commerce and work, relating to how society creates, buys, and consumes goods. In part, this is due to significant growth in online retailing and e-commerce but also a widespread change in the nature of work, where society is less reliant on manufacturing industry, with more onus on information and consumer services. These changes have consequences for the physical built environment. On the one hand, traditional bricks and mortar shops and large-scale manufacturing buildings face uncertain futures; on the other hand, new ways of working and consuming have fuelled demand for new types of buildings, for example large distribution warehouses (LDWs), located in close proximity to nodes of multi-modal connectivity. These buildings have been constructed in response to the aforementioned demand 
from distribution and logistics firms, much of which has been built in close proximity to junctions on national highway networks.

In turn, these changes in the built environment and land use have implications for those studying and working in the fields of urban (spatial) and economic planning. The changing nature of property markets requires recalibration of international planning and development perspectives, that need to identify, safeguard, and release land for LDWs situated in locations that benefit from high inter-modal connectivity. More broadly, the research will be of interest and relevance to a variety of market participants in manufacturing, distribution, and logistics sectors; industrial and warehouse tenants and owner occupiers; commercial and industrial sector landlords and investors; industrial and warehousing real estate agents and developers; inter-modal freight operators; and central and local government civil servants responsible for transport, spatial planning, and economic development.

Despite having been one of the most dynamic property market sectors of the last decade, distribution warehouse premises have received far less attention from researchers and market analysts than, for example, residential or commercial property market sectors, reminiscent of the Cinderella status previously afforded to their antecedents, industrial sheds. Although often existing in relatively peripheral locations, these buildings play a pivotal role in servicing urban and rural economies, via the distribution of vital goods, helping underpin society and the wider economy. Whilst distribution warehouses employ approximately half the full time equivalent employees of similarly sized industrial premisesaccording to Drivers Jonas Deloitte (2010), the employment density of large scale, high-bay warehouses is approximately half that of general and light industrial premises, at $80 \mathrm{~m}^{2}$ per full time employee (FTE) compared with $36 \mathrm{~m}^{2} /$ FTE for B2 General Industrial and $47 \mathrm{~m}^{2} /$ FTE for B1 Light Industrial uses-they are crucial components in the complex spatial ecology of the manufacturing and distribution of consumer goods, via increasingly sophisticated logistics networks, to satisfy ever demanding consumers, retailers, and suppliers. It is also worth noting that the growth in demand for LDWs in the UK has been accelerated by post-Brexit onshoring, driven by concerns about the resilience of global supply chains and the need for healthcare providers to store millions of items of personal protective equipment and other vital medical supplies to tackle the Covid-19 global pandemic.

It is this gap in knowledge that this article seeks to address through the lens of the industrial and distribution sector in England and Wales. The ambition of the research is to investigate, at a national scale, whether there has been a shift from established industrial and warehouse market locations, towards new patterns of location and land use, influenced by demand for premises from new and emerging sectors of the national economy. Whilst the research focuses on England and
Wales (in part due to the availability of reliable spatial data; see Section 3.1), the trends observed are similar to those being experienced by other countries with mature industrial property markets and growing warehouse and distribution sectors that serve, not only advanced manufacturing "just in time" production methods, but also the modern consumer requirements of "next day delivery" fulfilment, driven by the relentless growth in online shopping and e-commerce.

In order to examine this gap in knowledge, the article utilises a novel methodology founded upon national property taxation registers that are used to:

a) Map the location of industrial and warehouse premises in the England, between 2010 and 2020;

b) Record changes in the quantum and distribution of floorspace;

c) Reveal the areas where new industrial and warehouse development has been concentrated;

d) Shed light on some of the underlying drivers of some of the reported trends.

This is achieved by a bespoke geographical information systems (GIS) model that applies isochrone analysis. While the primary focus of this article is on England, it is important to note that the underlying data sets deployed in this study also cover Wales, while the travel distances include southern Scotland. The remainder of the article situates the research in wider literature, before setting out a novel and replicable methodology in detail, presenting and discussing the highly original results and findings, and offering final conclusions and contemplation of the significance of the research.

\section{Review of Literature}

Whilst commercial and industrial property location theories based on transport and factor costs, established by the likes of Alonso (1964), Isard (1956), Losch (1954), and Weber (1929) explain patterns of commercial and industrial activity that have prevailed in developed countries throughout the twentieth century, such theories may no longer explain twenty-first century commercial and industrial property market development trends. Traditionally, industrial facilities and premises were located close to sources of raw materials and power. The creation of employment opportunities then attracted workers and transport infrastructure was created to convey manufactured goods (Ball, 1984). Due to technological and socio-economic changes, these relationships have gradually been breaking down.

New economic geographers, such as Krugman (1991), have argued that transport costs, along with economies of scale, market size, and competition influence the location of industry. However, as Holl (2004) observes, transport infrastructure improvements can change the relative importance of concentrating (market size and agglomeration economies) and dispersing forces (factor 
costs and competition). Consequently, better transport connections can make areas of lower economic activity more attractive for firm location as they gain better access to markets in the core areas (Holl, 2004). Modern manufacturing is more footloose, with proximity to raw materials replaced by connectivity with distribution and logistics networks to serve just-in-time manufacturing processes in a move toward more distributed production networks (Matt et al., 2015).

Such trends have led to changes in planning policy: for example, The Town and Country (Use Classes) (Amendment) (England) Regulations 2020 (UK Government, 2020), which revoked the B1 Business Use Class (including light industrial) and created a new Commercial, Business and Service Class E, which places light industrial manufacturing within the commercial sector, whilst retaining B2 General Industrial and B8 Storage and Distribution as separate use classes. However, many local plans (the documents which, in the UK planning system, establish suitable locations for different types of new development) do not make a distinction between land allocated for B2 and B8 uses.

The relationship between spatial variables and the distribution of commercial and industrial property has been investigated in a variety of different countries and contexts. Seo et al. (2018) investigated commercial property values in relation to light rail and highway infrastructure in the US, considering both their negative and positive effects; Kadokawa (2018) investigated the relationship between manufacturing locations and the distance to highway interchanges in Japan; and Debrezion et al. (2010) investigated the relationship between commercial property value and proximity to railway stations in the Netherlands. Other researchers have considered the inter-relationship between a number of different variables. For example, Schoenmaker and Van der Vlist (2015) examined the relationship between commercial and residential real estate markets in the Netherlands, and Droj and Droj (2015) used locational analysis software to evaluate commercial real estate properties in Romania, resorting to GIS to map factors such as physical conditions, pollution, infrastructure, social conditions, and legal or planning constraints. Z. Yang et al. (2020) investigated the inter-relationship between new railway infrastructure, and the development of international logistics.

Particularly with reference to the research by Kadokawa (2018) and Debrezion et al. (2010), it is relevant to note that the importance of different modes of transport has changed over time. In the early nineteenth century, watercourses-natural and artificial-were the most important conduit for raw materials and goods. As the century progressed, railways became more important, and, in the twentieth century, the development of national highway networks as well as the increasing availability of motorised vehicles brought about modal shift towards road transport-not just for goods and raw materials, but also for employees and customers. Whilst the canal and river network in the UK are now less relied upon for transportation of bulk materials, rail freight still plays an important role not least because it produces $65 \%$ less $\mathrm{CO}_{2}$ than road freight (Laing \& Mofid, 2020).

Modal shift is particularly apparent in the warehousing and distribution sector, where changes in consumer preference from "bricks and mortar" to online retailing has not only had consequences for the retail sector and the performance and functionality of central business districts and out of town shopping centres, but also for complementary sectors such as distribution and logistics. Even before the Covid-19 pandemic, online retailing or e-commerce amounted to $19.1 \%$ of the total UK retail market in 2019 (Kotak \& Vezyridis, 2020). The Covid-19 pandemic of 2020-2021 has accelerated the trend, with online retail sales in the UK peaking at $31 \%$ of all sales in June 2020 (Dalgleish, 2021) leading to a crisis in "bricks and mortar" retail property, up to $40 \%$ of which may now be surplus to requirements (Greenhalgh, 2020).

Growth in online shopping increases demand for distribution warehouse premises, evidenced by property markets for large distribution warehousing registering strong demand and growth in the decade following the 2008-2013 recession. Whilst most new LDWs in the UK have been developed along the M1 motorway corridor (Jackson \& Rae, 2020), the North-West of England experienced large increase in take-up and development and the North-East and Yorkshire recorded its strongest ever performance, with a $170 \%$ increase above the long-term average, particularly large warehouses of over 100,000 sq. ft $\left(9,290 \mathrm{~m}^{2}\right)$ and "super-sheds" of over 500,000 sq. ft $\left(46,451 \mathrm{~m}^{2}\right.$; Mofid \& Asher, 2020). Access to major highways is becoming more, rather than less, important as growth of online retailing shifts the mechanism of supply towards warehouses from which goods are delivered directly to customers rather than via retailers (Kadokawa, 2018).

At the same time, technological development, and the take-up of new technologies, has permitted changes in the way warehouses operate. Picking and transporting goods within a warehouse, scanning, inventory, and documentation can all be automated. This has implications for the buildings themselves. According to Jackson et al. (2019), the specification of new LDWs typically includes $15-21 \mathrm{~m}$ bay heights, although $22-30 \mathrm{~m}$ baysfacilitating automated and robotic stock handling and picking at heights that forklift trucks cannot reachare becoming more common. The new taller breed of distribution warehouses is more voluminous, allowing insertion of space-saving mezzanine floors, and accommodate greater quantity of stock, operate around the clock 24/7, consume large amounts of electricity and, despite automation, still require a large nominal workforce (Jackson et al., 2019).

This raises the question as to whether factors influencing the optimal location of warehouse and distribution premises are the same as they were. Over the past three decades, a common pattern for logistics 
has been for goods to arrive at ports in the south of England, and then to be transported to warehouses in the "Golden Triangle" - an area lying in between Birmingham, Northampton, and Nottingham, from which it is estimated $90 \%$ of the UK's population can be reached in four hours journey time (Lupton, 2018). The goods are then transported by road to retailers and suppliers elsewhere in the country. Demand has remained strong over recent years, with $39 \%$ of all new warehouse leases in the UK having been taken within the Golden Triangle (Laing \& Mofid, 2020). However, due to high rents and property prices in the Golden Triangle, distribution and logistics operators have begun to look further afield for cheaper alternatives (Lupton, 2018). Laing and Mofid (2020) think it illogical and environmentally inefficient for goods bound for the north of the country to be shipped to the south coast, then transported by road to a central location, and then moved on by road to their final destination, when they could be shipped to the north of England. More sophisticated and intelligent logistics systems could allow a shipment of goods to be split at its origin into a northern and a southern shipment rather than arriving in Dover, Felixstowe, Southampton, or London Gateway and then being distributed via warehousing in the Golden Triangle.

This research seeks to exploit the availability of comprehensive national non-domestic (business) rating list data for England and Wales, to investigate what patterns of change can be observed in the size, distribution, number, and location of industrial and warehouse properties in England, between 2010 and 2020, and their relationship to the national highways network and major population centres.

\section{Methodology}

The methodology has been designed to address the previously identified gap in existing research, namely the lack of a comprehensive national level mapping and analysis of changes that have occurred to the quantum and distribution of industrial and warehouse premises in England and Wales over the last decade. The study exploits the capacity of GIS software to measure distances efficiently and accurately between premises and other geographical features, in this case LDWs, industrial premises and major junctions in the national highway network. This was pursued in order to validate the existence of a large cluster of LDWs in the Midlands, known as the Golden Triangle, and reveal whether other concentrations have emerged elsewhere in England and Wales, particularly in respect of "super sheds." The methodology deploys isochrone analysis of distance by average journey time for road freight in order to reveal the population of Great Britain within range of single heavy goods vehicle (HGV) journeys. Finally, the spatial analysis overlays the national rail freight network and strategic interchanges to reveal the proximity of inter-modal facilities with identified concentrations of LDWs.

\subsection{The Dataset}

In the UK, all non-residential property is taxed on the basis of its "rateable value," which is benchmarked and revalued by the Valuation Office Agency (VOA), on behalf of the Government, every five to seven years (Ministry of Housing, Communities and Local Government, 2020). Due to the predominantly privately-owned, complex, and fragmented tenure of commercial real estate in the UK, rateable values are calculated for hereditaments, which represent smaller units of property, rather than whole buildings. A hereditament is defined as:

A piece of real, inheritable and taxable property on which (business) rates can be charged. A hereditament generally corresponds to an extent of floor space suitable for a single occupant and might comprise a piece of land, a number of separate buildings, a single complete building, one or more floors within a building, or part of one floor. (Myers \& Wyatt, 2004, p. 288)

Properties in the VOA list are classified by bulk classes: industry, retail, office, and "other." The last category covers a range of different land uses, such as advertising rights, public houses, police stations and schools. Of those hereditaments where floorspace data are published, $60 \%$ of the total floorspace is industrial, $13 \%$ offices, $16 \%$ retail, and $11 \%$ "other". It is worth noting that, because different sectors generate hereditaments of different sizes, the relative shares by number of hereditaments is more evenly distributed across the bulk classes: $28 \%$ industrial, $22 \%$ offices, $27 \%$ retail, and $22 \%$ "other."

The bulk classes are classified into 369 special category (SCAT) codes which represent more specific land uses. The VOA states that within the industry sector, there are 20 SCAT codes, but admits that the relationship between sector and SCAT is not an exact science (VOA, 2020). In 2020, there were 49 SCAT codes within which at least some of the records were classed as "industry." However, for the purposes of this research, data for the following industrial, storage, and warehousing SCAT codes were used:

- 096 Factories, Workshops, and Warehouses;

- 151 Large Distribution Warehouses (LDWs);

- 153 Large Industrials over $20,000 \mathrm{~m}^{2}$.

These represent three of the four largest categories of industrial property, by floorspace, in the UK. The fourth category, land used for storage, is excluded because it consists of land rather than buildings which is not immediately relevant to the study of industrial and warehouse premises. The $20,000 \mathrm{~m}^{2}$ threshold for large industrial premises is consistent with the custom and practice of UK industrial agents to use 200,000 sq. $\mathrm{ft}$ (imperial measurement) as the threshold between regular and large 
industrial and warehouse premises in their market analyses. The dataset was analysed in four different ways, as illustrated in Figure 1. Firstly, the total floorspace, average floorspace, and number of units in each of the three categories were calculated.

Secondly, the records were geocoded by matching against an existing geocoded dataset of postcodes, and the straight-line distance between each unit and the nearest motorway junction (MJ) was calculated using the "join attributes by nearest" function in QGIS. The average distance from industrial unit to MJs, for each category of industrial property, in 2010 and 2020, could then be calculated. This also permitted calculation of the total floorspace and number of industrial units proximal to each MJ.

Thirdly, subsets of the 2010 and 2020 datasets were compared by matching Unique Address Reference Numbers (UARN) pertaining to each record. UARNs are allocated to hereditaments by the VOA and cease to exist when a property is redeveloped or another major change has taken place. Therefore, by matching datasets by UARN, it is possible to establish which units were present in both 2010 and 2020, which ones fell out of use, and which ones were newly constructed. It is also possible to track change-of-use by comparing the use class in 2010 with the use class in 2020.

Fourthly, isochrone analysis was carried out on MJs (using Open Roads Dataset-see Figure 1) and rail freight interchanges. Isochrone analysis has been well established as a tool for investigating accessibility and modelling the impact of a range of developments in relation to transport networks (see Fayman et al., 1995; O'Sullivan et al., 2000; L. Yang et al., 2020). 60-minute isochrones were calculated using the ORS Tools plugin for QGIS. Four-hour isochrones were calculated using the Network Analyst function on ArcMap, using Ordnance Survey OpenRoads data to create a model road network. An assumption was made that HGVs would travel at a maximum of 60 miles per hour ( $96 \mathrm{~km}$ per hour) on motorways and dual carriageways and 50 miles per hour (80 km per hour) on single carriageways. This takes account, firstly, the Department for Transport average speed statistics on the Strategic Road Network from 2015 to 2020 (Department for Transport, 2021); and, secondly,

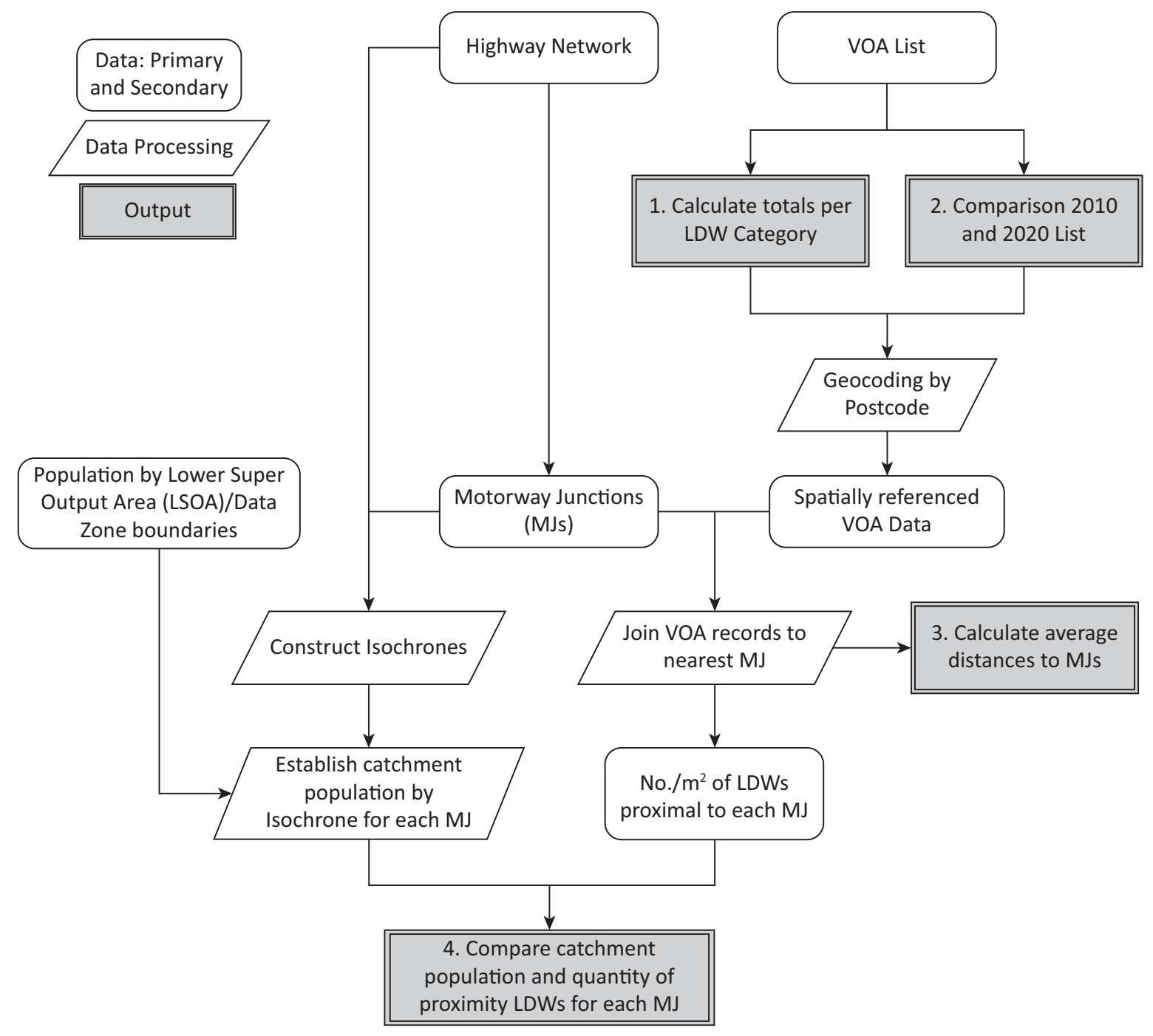

Figure 1. Research method and analysis flowchart. 
of UK speed limits for HGVs. These assumptions are, of course, open to question, since speeds vary considerably with time of day, weather and road conditions, and location. However, they provide us with a starting point for an approximate analysis of the effective catchment areas of each junction.

The resulting isodistance polygons were compared with a population map of the Great Britain, constructed by combining Scottish data zones and their estimated population for 2019 (National Records of Scotland, 2019; Scottish Government, 2011) with Lower Super Output Areas for England and Wales and their estimated population for 2019 (Office for National Statistics, 2016; Park, 2020). It was then possible to compare the population (as a proxy for the number of consumers that need to be supplied by distribution networks) within a four-hour isochrone of each MJ with the amount of LDWs floorspace proximal to it, and to establish whether any sort of relationship existed between the two. Thus, LDWs can be grouped by proximity to MJs, on the basis of which $\mathrm{MJ}$ is nearest permitting mapping of both the number of LDWs and the quantum of LDWs floorspace proximal to each MJ in 2010 and 2020.

\section{Results and Findings}

\subsection{Change in Industrial Property Size and Distribution Between 2010 and 2020}

\subsubsection{Change in Floorspace and Number}

Between 2010 and 2020, the total floorspace $\left(\mathrm{m}^{2}\right)$ of large industrials and factories, warehouses, and workshops in England and Wales decreased by $11.9 \%$ and $1.4 \%$ respectively. Factories and warehouses actually increased in number, but large industrials declined by $17.3 \%$. The total quantities of LDWs, however, increased by $21.9 \%$ by number and a significant $36.1 \%$ by area (Table 1).

\subsubsection{Change in Average Size}

LDWs have increased in size, as they have increased in number. The situation with other types of industrial property is a little less straightforward. On average, smaller industrial premises have increased in number but declined in size, so the total floorspace is almost the same. Large industrial properties, however, have increased in size but decreased in number. An alternative way of looking at the situation might be to say that, on average, industrial premises have tended to decline in size and that this is the cause of a modest decline in overall industrial floorspace between 2010 and 2020 (see Table 2).

\subsubsection{Distance to MJs}

Results confirm that proximity to motorways is more significant for LDWs than for other industrial uses. The average distance between a distribution warehouse and the nearest $\mathrm{MJ}$ is approximately half the comparable distance for a large industrial unit or a smaller industrial property. Analysing 2010 and 2020 records reveals that markets are polarising, with distance to MJs increasing for smaller industrial properties and decreasing for LDW and industrial units (Table 3).

\subsection{LDWs: Comparison Between New, Existing, and Defunct Units}

The majority of industrial properties of all kinds were present both in 2010 and 2020. A comparison between units that ceased to exist, and those which persist, can help understand processes that are taking place. Underlying changes in stock, as a response to occupier demand, register as changes in the average size of a category of property. For example, an increase in average size could be due a combination of lost units being smaller, new units being larger or persisting units growing in size,

Table 1. Change in floorspace $\left(\mathrm{m}^{2}\right)$ and number of units by category, 2010-2020.

\begin{tabular}{lccc}
\hline & & SCAT Description & \\
\cline { 2 - 4 } Dataset & $\begin{array}{c}\text { Factories, Workshops, } \\
\text { and Warehouses }\end{array}$ & $\begin{array}{c}\text { Large Industrials } \\
\left(\text { Over } 20,000 \mathrm{~m}^{2}\right)\end{array}$ \\
\hline Aggregate in $\mathrm{m}^{2}, 2010$ & $237,433.187$ & $27,440.932$ & $36,885.484$ \\
Aggregate in $\mathrm{m}^{2}, 2020$ & $234,046.777$ & $37,338.878$ & $32,492.964$ \\
Change in $\mathrm{m}^{2}$, 2010-2020 & $-3,386.409$ & $9,897.945$ & $-4,392.520$ \\
Change in \%, 2010-2020 & -1.4 & 36.1 & -11.9 \\
Number of units, 2010 & 337,582 & 1,113 & 1,099 \\
Number of units, 2020 & 365,859 & 1,357 & 909 \\
Change in number, 2010-2020 & 28,277 & 244 & -190 \\
Change in \%, 2010-2020 & 8.4 & 21.9 & -17.3 \\
\hline
\end{tabular}


Table 2. Change in average size of industrial premises $\left(\mathrm{m}^{2}\right)$ by category, 2010-2020.

\begin{tabular}{lccc}
\hline & \multicolumn{3}{c}{ SCAT Description } \\
\cline { 2 - 4 } Dataset & $\begin{array}{c}\text { Factories, Workshops, } \\
\text { and Warehouses }\end{array}$ & LDWs & $\begin{array}{c}\text { Large Industrials } \\
\text { (Over 20,000 } \mathrm{m}^{2} \text { ) }\end{array}$ \\
\hline Average in $\mathrm{m}^{2}, \mathbf{2 0 1 0}$ & 703 & 24,655 & 33,563 \\
Average in $\mathrm{m}^{2}, \mathbf{2 0 2 0}$ & 640 & 27,516 & 35,746 \\
Change in $\mathrm{m}^{2}, \mathbf{2 0 1 0 - 2 0 2 0}$ & -64 & 2,861 & 2,183 \\
Change in \%, 2010-2020 & -9 & 11.6 & 6.5 \\
\hline
\end{tabular}

Table 3. Distance (m) to MJ by category, 2010-2020.

\begin{tabular}{lccc}
\hline & \multicolumn{3}{c}{ SCAT Description } \\
\cline { 2 - 4 } Dataset & $\begin{array}{c}\text { Factories, Workshops, } \\
\text { and Warehouses }\end{array}$ & LDWs & $\begin{array}{c}\text { Large Industrials } \\
\left(\text { Over } 20,000 \mathrm{~m}^{2} \text { ) }\right.\end{array}$ \\
\hline Average distance in $\mathrm{km}, \mathbf{2 0 1 0}$ & 14.982 & 6.697 & 12.600 \\
Average distance in $\mathrm{km}, \mathbf{2 0 2 0}$ & 15.272 & 6.385 & 12.178 \\
Average change in $\mathrm{m}, \mathbf{2 0 1 0 - 2 0 2 0}$ & 290 & -312 & -422 \\
Change in \%, 2010-2020 & 1.9 & -4.7 & -3.3 \\
\hline
\end{tabular}

or a combination of two or three of these. The average size of LDWs increased because the average size of lost units was lower than average, the size of new units greater than average, and because persistent units increased slightly in size over the period. Similarly, lost units were slightly further away from MJs than the average for 2010, and new units were closer than the average for 2020.

Perhaps the most significant observation is that there were many more new units than persistent or lost ones, a key finding being that units which contribute the most to the characteristics of the sector are those constructed in the last ten years. Despite increased bay heights, average building footprints have also continued to increase, as have yard depths and car parking, thus requiring more land (Jackson et al., 2019). Of the 20 largest "super sheds" built in 2020 , all were over $100,000 \mathrm{~m}^{2}$; of these, 14 belonged to individual retail companies that also have a physical retail presence (of which four belonged to
Next); three belonged to Amazon; and three belonged to logistics companies (see Figure 2). Most very large warehouses are bespoke, typically procured and constructed under design and build contracts (Jackson et al., 2019), and are suitable only for the purpose for which they were originally constructed (see Table 4).

Having established that the number and floorspace of LDWs in England and Wales has increased in the past ten years, the next section considers where this increase has taken place, and why.

\subsection{Relationship Between LDWs Location and Access to Customers}

LDWs locate in close proximity to MJs; on average, they are less than $7 \mathrm{~km}$ away from MJs, well below the average distance to MJs of the other industrial categories covered by this study. Their distance to MJs is declining over time, as newer units tend to be built slightly closer to MJs

Table 4. Characteristics of new, lost, and persisting LDWs, 2010-2020.

\begin{tabular}{lcccccc}
\hline & All units, 2010 & Lost units & All units, 2020 & New units & $\begin{array}{c}\text { Persistent } \\
\text { units, 2010 }\end{array}$ & $\begin{array}{c}\text { Persistent } \\
\text { units, 2020 }\end{array}$ \\
\hline Number of units & 1,113 & 451 & 1,357 & 695 & 662 & 662 \\
Aggregate in $\mathrm{m}^{2}$ & $27,440,932.00$ & $10,303,661.00$ & $37,338,878.00$ & $20,013,185.00$ & $17,137,271.00$ & $17,325,692.00$ \\
Average in $\mathrm{m}^{2}$ & $24,654.90$ & $22,846.30$ & $27,515.80$ & $28,795.90$ & $25,887.10$ & $26,171.70$ \\
$\begin{array}{l}\text { Average } \\
\text { distance }(\mathrm{m})\end{array}$ & 6,697 & 6,824 & $6,381.20$ & $6,170.50$ & $6,610.60$ & $6,602.40$ \\
to MJ & & & & & & \\
\hline
\end{tabular}




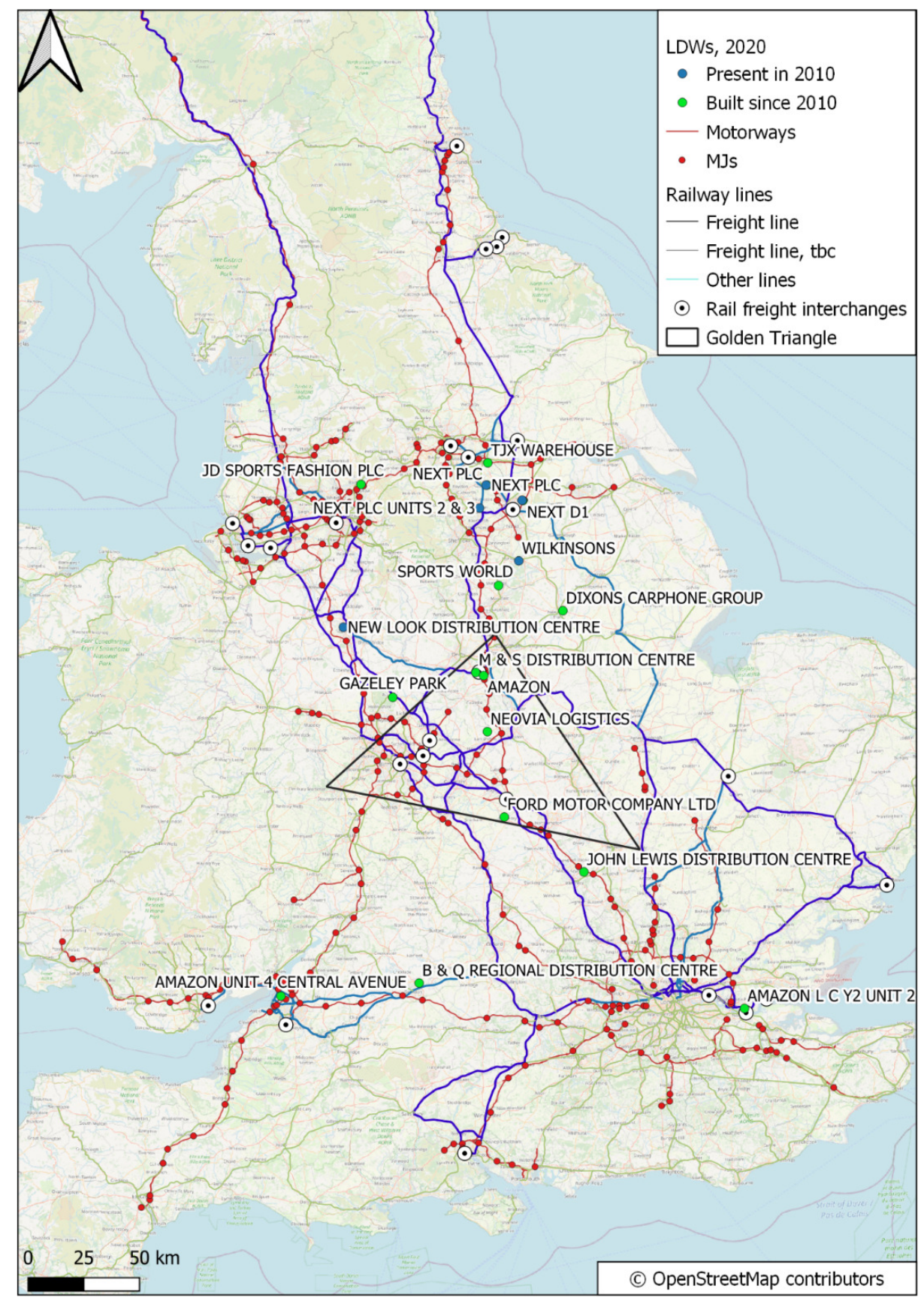

Figure 2. Location of the 20 largest LDWs, 2020.

than older ones. LDWs in the Golden Triangle are in high demand, as evidenced by occupier (demand) side indicators such as high rental and capital values. This is due to their coveted locational position within the national motorway network, as well as proximity to the international rail freight network (Daventry International Rail Freight Terminal is located at the heart of the Golden Triangle; Lupton, 2018). This raises the question as to whether there are locations within our study area that are competing with, or have the potential to challenge, those in the Golden Triangle. Some initial observations are possible.

Firstly, the Golden Triangle, as it is commonly defined (see RCS Logistics, 2020), is not a very precise represen- tation of the location of LDWs in the UK, which is a compelling reason to pursue a contemporary, comprehensive, and accurate spatial analysis of the sector. There is an area of the Midlands which is a popular location for LDWs but according to our analysis, it extends further south-east along the M1 corridor towards London and extends across the conurbation of Birmingham and Wolverhampton. We have tentatively outlined this area in Figure 3, naming it the "Golden Pointer."

Secondly, there is a large area in the north of England, covering Leeds, Sheffield, Doncaster, Liverpool, and Manchester, that has a concentration of LDWs floorspace. Again, we have tentatively outlined it in Figure 3, under the name "Northern Dumbbell." Growth 
is also seen along the $\mathrm{M} 1$ and $\mathrm{A} 1$, at Peterborough, and around London and Bristol.

Thirdly, MJs that had a large amount of proximal LDWs floorspace in 2010 tended to have an even larger amount of LDWs floorspace in 2020, whereas the majority of MJs (385 out of 668 in 2020 or $58 \%$ ) had no proximal LDWs at all. Significantly, by 2020, the majority of all LDWs floorspace in England and Wales were located either in the Golden Pointer or the Northern Dumbbell (22.5\% and 30.3\% respectively). Between 2010 and 2020, LDWs floorspace overall grew by $36.07 \%$; but growth was unevenly distributed, with the Golden Pointer growing by $44.8 \%$ and the Northern Dumbbell by $44.1 \%$ whilst the remainder of England and Wales recorded growth of only $27.7 \%$.
Certain MJs underwent intensive development between 2010 and 2020. Five junctions, indicated in Figure 3, saw a ten-fold increase in proximal LDWs floorspace (>1000\%): three in the Northern Dumbbell (J3 of the M606, J28 of the M6, and J8 on the M62), one near London (J11 of the M4), and only one in the Golden Pointer (J24A of the M1). Since the popularity of the Golden Pointer is due to its proximity to the majority of the UK's population, we can hypothesise that the popularity of junctions with a large amount of proximal LDWs floorspace is also linked to their proximity to centres of population.

Analysis appears to show that Northern Dumbbell locations are beginning to compete, in terms of market rent and status, with the Golden Pointer, providing either

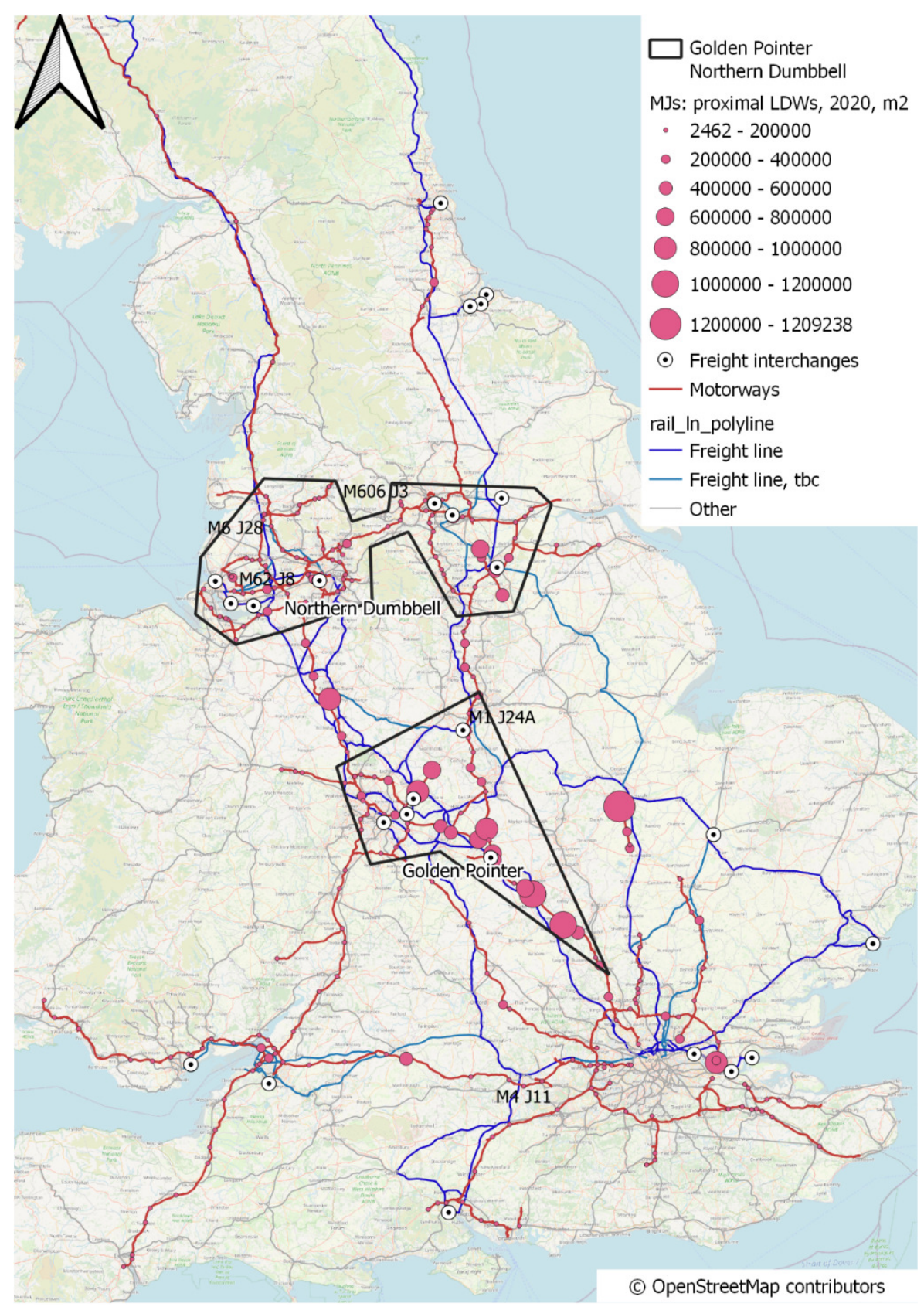

Figure 3. LDW floorspace $\left(\mathrm{m}^{2}\right)$ proximal to MJs, 2020. 
an alternative or complementary location from which the majority of the country's population can be reached within four-hour haulage drive time. This is consistent with Laing and Mofid's (2020) observation that distributors are beginning to select two bases within the UK, one in the Midlands and one in the North of England. This can be demonstrated by comparing the isochrone polygon for Junction 38 of the A1-the junction in the Northern Dumbbell with the largest amount of proximal LDWs floorspace-and the corresponding isochrone polygon for Junction 20 of the $\mathrm{M} 1$, the most popular junction in the Golden Pointer. The former extends northwards to reach the major centres of Glasgow and Edinburgh, and south to cover London, Bristol, and their hinter- lands. In comparison, junctions in the Golden Pointer are within reach of a slightly different subset of the Great Britain, extending to cover almost all of Wales and the South Coast, but not including Edinburgh and Glasgow (see Figure 4).

While junctions within the Golden Triangle (or Pointer) still form a reliable and consistent way of accessing over $85 \%$ of the population, the most popular junctions elsewhere in the country-defined here as the junctions with the largest number of proximal LDWs-are able to reach a comparable proportion of the population. Junctions to the south and east of the Golden Pointer, and those to the north of the Northern Dumbbell, tend to have lower catchment populations (i.e., lower numbers

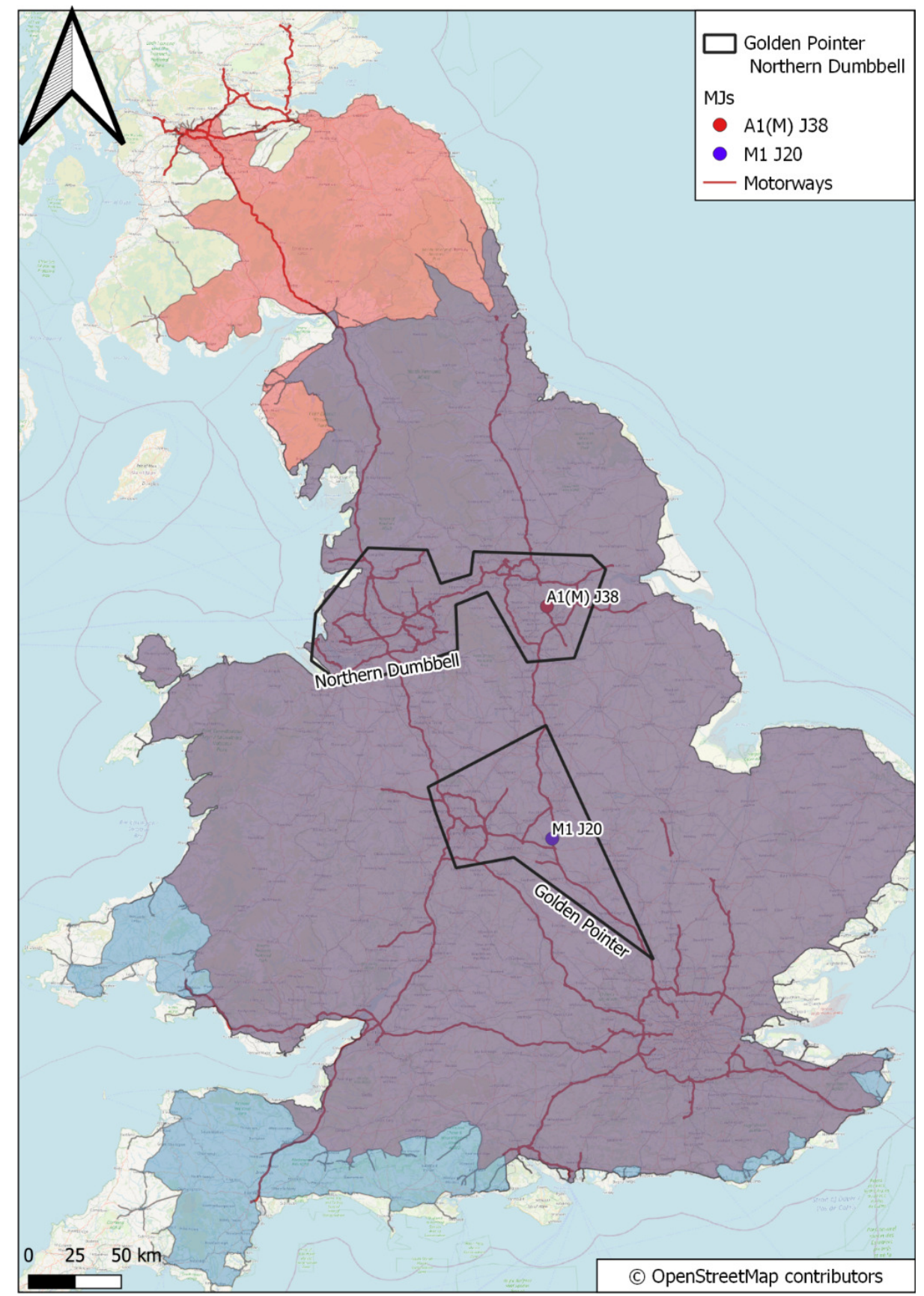

Figure 4. Four-hour isochrones for junction 38 of the $A 1$ and junction 20 of the M1. 
of people within their four-hour isochrones). This is not the case for the two corridors (M1 and M6) between the Golden Pointer and Northern Dumbbell, which have some of the highest catchment populations in the country (see Figure 5).

Three other factors may be relevant to the location of LDWs. The first is the cost of premises. Broadly speaking, LDWs premises are more expensive the closer they are to Greater London and the M25 in the south-east of England, where land and property prices are higher than locations further north and west (Statista, 2021).

The second is whether premises exist, or can be found, close to MJs. The area in between the Golden
Triangle and the Northern Dumbbell contains some of the MJs with the largest catchment populations. However, because this area does not contain many motorways-due to the Pennine Hills at its centreLDWs here are limited to the corridors of the M6, M1, and A1. Elsewhere, there are some MJs with little or no proximal LDWs space, despite being in an area with many LDWs and high catchment populations; these may be locations where there are few suitable sites.

A third factor may be the distance to the rail freight network, or rather, to rail freight interchanges, of which there are 25 in England and Wales and another five in Scotland (NetworkRail, 2020). Mapping of strategic

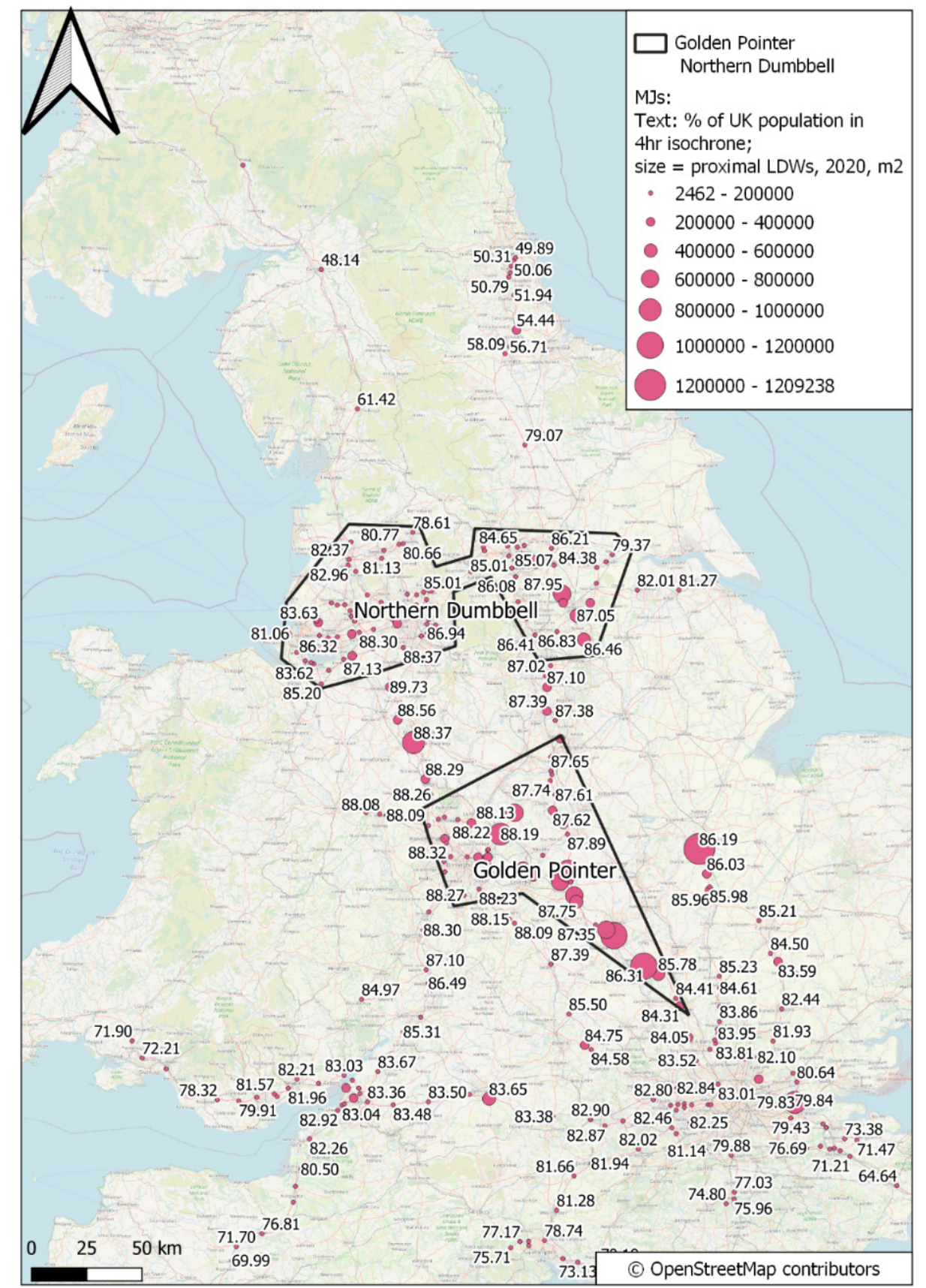

Figure 5. Junctions with proximal LDW development (2020) and isochrone population as a percentage of total UK population, 2020. 
rail-freight interchanges confirms that the three largest clusters of interchanges sit within the Golden Pointer and either side of the Northern Dumbbell, as shown in Figure 6 . The fact that $61.7 \%$ of all LDWs floorspace in England and Wales is within a 30-minute drive of a rail freight interchange would suggest that this is no coincidence (see AECOM, 2010; Intermodality, 2009).

\section{Discussion and Conclusions}

The research addresses a deficit of empirical study in relation to the increased quantity and concentration of LDWs in England and Wales between 2010 and 2020. In doing so, the article reveals the significance of proxim- ity to population centres, MJs, and strategic rail freight hubs as determinants of location. The research explored the divergence between LDWs and other types of industrial premises and reveals the emergence of a new cluster of distribution warehouses that we have named the "Northern Dumbbell" to rival the already well recognized "Golden Triangle" in the Midlands. Identification, geo-location, and quantification of the existence of this new cluster of distribution warehouses is an original and significant finding of the research, contributing to a better understanding of recent dynamic activity in the distribution warehouse sector in the UK. The findings should be of interest and relevance to policy makers and market participants alike. Having created and

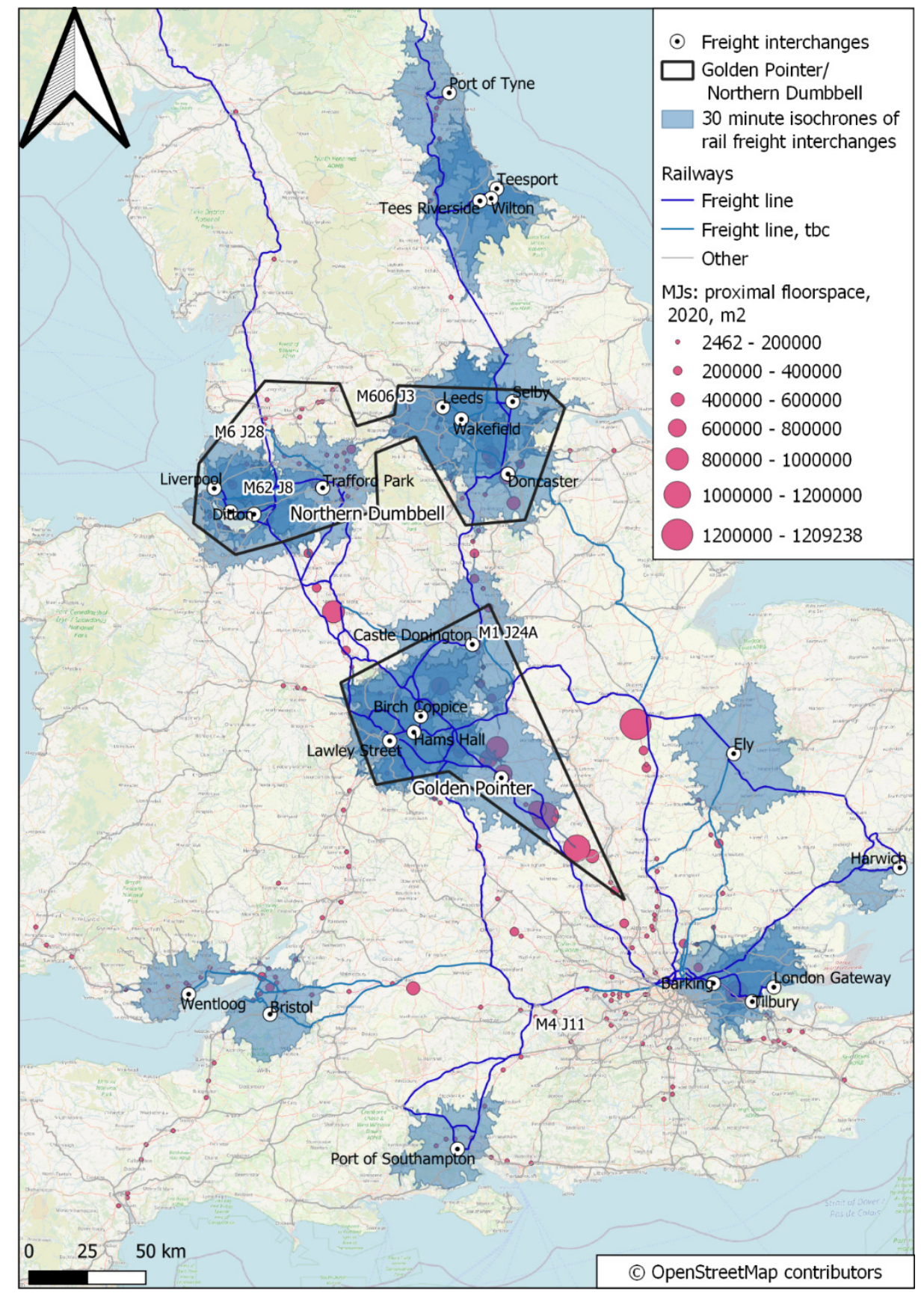

Figure 6. 2020 LDWs with 30-minute isochrones of rail freight interchanges. 
tested an effective method for analysing and representing changes that have occurred in the quantum and distribution of new industrial and distribution warehousing in England and Wales, there is now the opportunity to conduct comparative studies in other countries with mature industrial markets to identify whether similar sectoral trends can be identified. The method permits the measurement of proximity of premises to junctions in national highway networks and calculation of the population within reach of LDWs calculated with reference to average HGV speed and maximum single journey drive time. The GIS can also integrate national transport infrastructure such as rail freight networks and strategic inter-modal and multi-modal interchanges, such as rail freight interchanges, airports, and deep-water container port facilities.

According to our research, covering England and Wales, over the last decade there has been a decline in industrial floorspace, as defined by the VOA ("Factories, Workshops, and Warehouses" and "Large Industrials") whilst there has been significant increase in LDWs. Total LDWs floorspace has increased by 36\% between 2010 and 2020, coinciding with strong growth in online retailing (see Dalgleish, 2021) which has driven demand for more and bigger warehouses to support distribution and fulfillment activity in the UK. Concomitantly, spatiotemporal analysis has revealed that new LDWs are being built closer to highway junctions, with average distances between LDWs and the nearest MJ decreasing over the last decade.

The "Golden Triangle," an area in the Midlands between Birmingham, Northampton, and Nottingham, was already recognized as the UK's primary cluster of LDWs due, in part, to $90 \%$ of the UK's population being within four hours travel time, and the area being accessible to strategic ports in the southeast of England. According to our research, between 2010 and 2020, LDW floorspace in the Golden Triangle grew by 44.8\%. However, the Golden Triangle's boundaries did not correspond entirely to the pattern of LDW growth in the Midlands. A revised "Golden Pointer" has been identified and tentatively suggested as a more accurate representation of the Midland cluster, including more of the Birmingham/Wolverhampton conurbation and units along the M1 towards London. Growth was also observed around MJs further north, and around Peterborough. Our research also revealed a new rival and previously un-recorded concentration of LDW premises that we have named the "Northern Dumbbell," covering Leeds, Sheffield, Doncaster, Liverpool, and Manchester. Between 2010 and 2020, LDW floorspace in the Northern Dumbbell increased by $44.1 \%$. By 2020 , the majority of all LDW floorspace in England and Wales was found either within the Golden Pointer or Northern Dumbbell. According to our isochrone calculations, the proportion of the population of Great Britain that can be reached from the Northern Dumbbell is almost as great as that within reach from the Golden Triangle. Significantly, whilst the Golden Pointer is within four hours journey time of almost all of England and Wales, it is not within reach of Scotland's central belt between Edinburgh and Glasgow; whilst the Northern Dumbbell cannot reach the south-west of England and Wales, it is within four hours drive time of the Scottish Central Belt. It appears that distribution and logistics operators are seeking better value premises in locations outside of the "traditional" Golden Triangle, simultaneously moving towards a two-centre distribution model, one serving northern England and the Scottish central belt and the other covering the midlands and southern England. The emerging Northern Dumbbell also appears to be exploiting the strength of the rail freight network in the north of England. An opportunity for further study is to use kernel density analysis or similar techniques to analyse these locations more rigorously to verify that the "Northern Dumbbell" is a discrete location for distribution and logistics operators, but also whether it rivals or complements the "Golden Pointer" in the Midlands as the prime location for distribution warehousing in the UK.

These findings, into the changing nature of industrial property markets, occurring in response to structural changes in international modes of work, should form a sound basis and early staging post for planners, and associated professionals, in the international community as they consider competing demands on land in strategic locations in relation to national highway and transport networks and nodes. As hinted at in the early part of this article, due to the sheer size of these buildings and the area of land required to accommodate not only the footprint of the building but also ancillary external infrastructure, spatial and land-use planners and transport strategists may need to review their approaches to the allocation, zoning, and designation of land for warehouse and storage use in proximity to existing transport infrastructure and multi-modal interchanges.

There is a need for further research into the mapping and modelling of alternative calculations of drive times and distances, alongside exploration of other ways of capturing the variable ratio of population reached by distance travelled (or time spent travelling) and consideration of the interaction between other variables that may make sites and premises more or less attractive to occupiers.

Another issue for further consideration is the role of A roads - the second most important group of roads in the UK, after motorways. In some locations, they perform the same function as motorways and are counted as part of the Strategic Road Network. Currently there is no standard subset of strategic junctions on A roads that have a similar function to MJs, thus they were excluded from the study; however, if this challenge could be overcome then they could be included within the analysis.

As we have discussed, the rental value of LDW premises varies across Great Britain, with the highest rents and land prices around the M25 London orbital motorway, pushing both developers and occupiers of 
"space hungry" distribution warehouses away from expensive locations towards more affordable ones. Reassuringly, the underpinning logic of commercial and industrial property location theories of Alonso (1964), Isard (1956), Losch (1954), and Weber (1929), that there is a trade-off between cost, availability, and location, appears to still be pertinent in today's highly connected consumption driven economy.

Finally, the spatio-temporal method and analysis presented in this article offers potential to further explore the changing relationships between increasingly dynamic commercial and industrial sectors, and the response of real estate markets to changing occupier demands and fixed national transport infrastructure. For example, a contemporary issue in the post-Brexit UK is that of freeports (locations that are outside their geographical country for tax purposes, within which little or no taxes or tariffs are paid). The UK Government invited bids for freeport status from across the UK with the expectation of seven being designated in England and one each in Wales, Scotland, and Northern Ireland, with successful applicants benefitting from a wide package of tax reliefs, simplified customs procedures, streamlined planning processes to boost redevelopment, and government support to promote regeneration and innovation (HM Treasury, 2020; HM Treasury \& Ministry of Housing, Communities and Local Government, 2021). In the latest Budget (HM Treasury, 2021), Chancellor Rishi Sunak confirmed approval of eight freeports in England, with further announcements of freeport designation in Wales, Scotland, and Northern Ireland anticipated. There is an urgent need to examine their potential to function as holding bays, or distribution centres, facilitating smoother flow of "tariff free" goods between the UK (including Northern Ireland) and both mainland Europe and the Republic of Ireland, with tariffs only paid when the goods are moved elsewhere (Laing \& Mofid, 2020). The method presented in this article offers an analytical tool with which to evaluate and monitor how industrial and warehouse markets respond to the designation of incentivised locations.

\section{Conflict of Interests}

The authors declare no conflict of interests.

\section{References}

AECOM. (2010). Strategic distribution site: Assessment study for the three cities sub-area of East Midlands. Final report. https://www.nwleics.gov.uk/files/ documents/strategic_distribution_site_assessment_ east_midlands_study_final_report_may_2010/ Strategic\%20Distribution\%20Site\%20Assessment \%20East\%20Midlands\%20Study\%20Final\%20 Report\%20-\%20May\%202010.pdf

Alonso, W. (1964). Location and land-use. Toward a general theory of land rent. Harvard University Press.
Ball, M. (1984). The spaced out urban economy. In D. Massey (Ed.), Geography matters (pp. 68-84). Open University Press.

Dalgleish, R. (2021). Internet sales as a percentage of total retail sales (ratio) (\%). Office for National Statistics. https://www.ons.gov.uk/businessindustry andtrade/retailindustry/timeseries/j4mc/drsi

Debrezion, G., Pels, E., \& Rietveld, P. (2010). The impact of rail transport on real estate prices. Urban Studies, 48(5), 997-1015. https://doi.org/10.1177/ 0042098010371395

Department for Transport. (2021). Average speed, delay and reliability of travel times (CGN). https://www. gov.uk/government/statistical-data-sets/averagespeed-delay-and-reliability-of-travel-times-cgn

Drivers Jonas Deloitte. (2010). Employment densities guide (2nd ed.). https://assets.publishing.service. gov.uk/government/uploads/system/uploads/ attachment_data/file/378203/employ-den.pdf

Droj, L., \& Droj, G. (2015). Usage of location analysis software in the evaluation of commercial real estate properties. Procedia Economics and Finance, 32, 826-832. https://doi.org/10.1016/s2212-5671 (15)01525-7

Fayman, S., Metge, P., Spiekermann, K., Wegener, M., Flowerdew, T., \& Williams, I. (1995). The regional impact of the channel tunnel: Qualitative and quantitative analysis. European Planning Studies, 3(3), 333-356. https://doi.org/10.1080/ 09654319508720310

Greenhalgh, P. (2020, October 22). Up to $40 \%$ of UK retail space is not needed-Here's what can be done with it. The Conversation. https://theconversation.com/ up-to-40-of-uk-retail-space-is-not-needed-hereswhat-can-be-done-with-it-148556

HM Treasury. (2020). Freeports bidding process opens for applications. https://www.gov.uk/government/ news/freeports-bidding-process-opens-forapplications

HM Treasury. (2021). Budget 2021: Protecting the jobs and livelihoods of the British people. https:// assets.publishing.service.gov.uk/government/ uploads/system/uploads/attachment_data/file/ 966868/BUDGET_2021_-_web.pdf

HM Treasury, \& Ministry of Housing, Communities and Local Government. (2021). Freeports bidding prospectus. https://www.gov.uk/government/ publications/freeports-bidding-prospectus

Holl, A. (2004). Manufacturing location and impacts of road transport infrastructure: Empirical evidence from Spain. Regional Science and Urban Economics, 34(3), 341-363. https://doi.org/10.1016/S01660462(03)00059-0

Intermodality. (2009). Rail freight interchange facilities for South Holland District: Summary report. http://www.southeastlincslocalplan.org/wpcontent/uploads/2012/02/Rail-freight-interchangefacilities-for-South-Holland-District-Summary- 
Report-November-2009.pdf

Isard, W. (1956). Location and space-economy: A general theory relating to industrial location, market areas, land use, trade and urban structure. MIT Press.

Jackson, A., \& Rae, R. (2020). Big box bulletin: Halfyearly update of distribution activity. H1 2020. Avison Young. https://www.avisonyoung.co.uk/bigbox-bulletin-h1-2020

Jackson, A., Rae, R., \& Tebbits, G. (2019). The rising warehouse: Man and machine. Avison Young. https:// www.avisonyoung.co.uk/documents/38901/ 59345308/The+rising+warehouse+-+man+and+ machine.pdf

Kadokawa, K. (2018). Highway access and the critical distance to an industrial location: A survival analysis. GeoJournal, 84(1), 31-54. https://doi.org/10.1007/ s10708-018-9846-7

Kotak, H., \& Vezyridis, T. (2020). UK logistics viewpoint: Mild symptoms for industrial property. CBRE. https://www.cbre.co.uk/research-and-reports/UKLogistics-ViewPoint-Mild-Symptoms-for-IndustrialProperty

Krugman, P. (1991). History and industry location: The case of the manufacturing belt. The American Economic Review, 81(2), 80-83.

Laing, W., \& Mofid, K. (2020). Traditional logistics versus 21st-century demands. Savills. https://www. savills.co.uk/research_articles/229130/307719-0/ traditional-logistics-vs-21st-century-demands

Losch, A. (1954). The economics of location. Yale University Press.

Lupton, K. (2018). Is the 'Golden Triangle' still the centre of UK logistics? Bis Henderson Space. https:// www.bis-hendersonspace.com/is-the-goldentriangle-still-the-centre-of-uk-logistics

Matt, D. T., Rauch, E., \& Dallasega, P. (2015). Trends towards distributed manufacturing systems and modern forms for their design. Procedia CIRP, 33, 185-190. https://doi.org/10.1016/j.procir.2015. 06.034

Ministry of Housing, Communities and Local Government. (2020). Business rates revaluation postponed. https://www.gov.uk/government/news/businessrates-revaluation-postponed

Mofid, K., \& Asher, T. (2020). The logistics market in Yorkshire and the North East. Savills. https://www.savills. co.uk/research_articles/229130/302066-0

Myers, D., \& Wyatt, P. (2004). Rethinking urban capacity: Identifying and appraising vacant buildings. Building Research \& Information, 32(4), 285-292. https:// doi.org/10.1080/0961321042000221061

National Records of Scotland. (2019). Mid-2019 small area population estimates for 2011 data zones. https://www.nrscotland.gov.uk/statistics-anddata/statistics/statistics-by-theme/population/ population-estimates/2011-based-special-areapopulation-estimates/small-area-populationestimates/mid-2019
NetworkRail. (2020). Rail freight. https://www. networkrail.co.uk/industry-and-commercial/railfreight

O'Sullivan, D., Morrison, A., \& Shearer, J. (2000). Using desktop GIS for the investigation of accessibility by public transport: An isochrone approach. International Journal of Geographical Information Science, 14(1), 85-104. https://doi.org/10.1080/ 136588100240976

Office for National Statistics. (2016). Lower layer super output area (LSOA) boundaries. https://data.gov.uk/ dataset/fa883558-22fb-4a1a-8529-cffdee47d500/ lower-layer-super-output-area-Isoa-boundaries

Park, N. (2020). Lower layer super output area population estimates (National statistics) [Data set]. Office for National Statistics. https://www.ons.gov. uk/peoplepopulationandcommunity/population andmigration/populationestimates/datasets/ lowersuperoutputareamidyearpopulation estimatesnationalstatistics

RCS Logistics. (2020, January 29). The Golden Triangle of logistics. https://www.rcslogistics.co.uk/blogand-news/golden-triangle/2935

Schoenmaker, D. A. J., \& Van der Vlist, A. J. (2015). On real estate development activity: The relationship between commercial and residential real estate markets. Letters in Spatial and Resource Sciences, 8(3), 219-232. https://doi.org/10.1007/s12076-0150144-4

Scottish Government. (2011). Data zone boundaries. https://spatialdata.gov.scot/geonetwork/srv/eng/ catalog.search\#/metadata/7d3e8709-98fa-4d71867c-d5c8293823f2

Seo, K., Salon, D., Kuby, M., \& Golub, A. (2018). Hedonic modeling of commercial property values: Distance decay from the links and nodes of rail and highway infrastructure. Transportation, 46(3), 859-882. https://doi.org/10.1007/s11116-018-9861-z

Statista. (2021). Annual primary rent costs for warehouses in the occupier logistics market for select cites of the United Kingdom (UK) from the 4th quarter 2014 to the 4th quarter 2020. https://www.statista. $\mathrm{com} /$ statistics/527827/warehouse-primary-rentcost-logistics-market-united-kingdom-uk

UK Government. (2020). The town and country (use classes) (amendment) (England) regulations 2020 (SI 2020/757). https://www.legislation.gov.uk/uksi/ 2020/757/contents/made

Valuation Office Agency. (2020). Non-domestic rating: Stock of properties including business floorspace. Background Information. https://assets.publishing. service.gov.uk/government/uploads/system/ uploads/attachment_data/file/820492/ Background_Information.pdf

Weber, A. (1929). Theory of the location of industries. The University of Chicago Press.

Yang, L., Chu, X., Gou, Z., Yang, H., Lu, Y., \& Huang, W. (2020). Accessibility and proximity effects of bus 
rapid transit on housing prices: Heterogeneity across price quantiles and space. Journal of Transport Geography, 88, Article 102850. https://doi.org/10.1016/ j.jtrangeo.2020.102850

Yang, Z., Sun, Y., \& Lee, P. T.-W. (2020). Impact of the development of the China-Europe Railway ExpressA case on the Chongqing international logistics center. Transportation Research Part A: Policy and Practice, 136, 244-261. https://doi.org/10.1016/ j.tra.2020.03.022

\section{About the Authors}
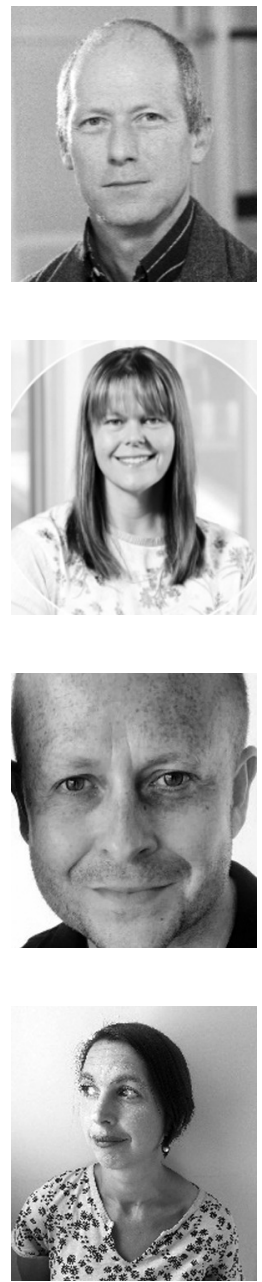

Paul Greenhalgh is Professor of Real Estate and Regeneration at Northumbria University, a member of the Royal Institution of Chartered Surveyors, Founder of the URBaNE research group, R3intelligence consultancy, and Curator of the North East Regeneration Archive (NERA). His fields of expertise are commercial property markets and real estate planning and development. He is currently exploring the potential to use Geographic Information Systems to visualise and analyse commercial real estate markets.

Helen M. King is a Senior Lecturer in GIS at Northumbria University. Helen is interested in developing appropriate applications of GIS in order to conduct research and consultancy projects. This includes developing new methodologies incorporating visibility analysis, cartographic modelling, landscape character assessment, qualitative data (tranquillity, sense of community ownership, and property chaining), and new developments in geospatial technologies in answering research questions.

Kevin Muldoon-Smith is a Senior Lecturer in Built Environment Adaptation and Investment in the Department of Architecture and Built Environment at Northumbria University and Co-Founder of R3intelligence Consultancy. After several years working in the field of urban regeneration, he transitioned into academia, conducting initial research into building obsolescence and adaptive re-use before making contributions in the domains of local government funding and property taxation alongside methods and processes of knowledge transfer.

Josephine Ellis worked in planning and local government for two decades before joining academia. She also works as a Freelance Planning Consultant under the name of Blue Kayak Planning. Her research interests include sustainability in cities, active and public transport, the spatial and temporal evolution of the built environment, and toponymy and regulation by discourse in the built environment. 